\title{
Integrating biodiversity conservation and ecosystem services into operational plan of community forest in Nepal : status and gaps
}

\author{
P. R. Thani ${ }^{*}$, R. KC ${ }^{2}$, B. K. Sharma ${ }^{1}$, P. Kandel ${ }^{1}$ and K. Nepal ${ }^{1}$
}

\begin{abstract}
After initiation of community forestry system in Nepal, the status of forest cover has improved due to significant roles of people in conservation, management and utilization of forest resources. As a result of increased productivity of the forest and restoration of degraded areas, forest users have been able to receive various economic, social, cultural and environmental benefits to strengthen their livelihood. Despite many positive outcomes of community forestry, there are still some factors which haven't allowed the proper biodiversity conservation and ecosystem services maintenance. The study carried out on 100 operational plans from different parts of the country and it showed that the incorporation status of biodiversity and ecosystem services into community forest operational plan is worse despite the fact that such plan is the main component to lead the destination of any community forest. In addition to this, some gaps and challenges were observed in community forestry which have not favoured to biodiversity conservation and ecosystem services management systematically at an optimum level. Among them, duplication problem of biodiversity and ecosystem services related issues in operational plan; timber oriented operational plan; limited provision about wildlife conservation and negative perception of people on wildlife and their conservation owing to human wildlife conflict; dominant socioeconomic factors; impact of introduced species, invasive and alien species; lacking in provision of adaptation and mitigation methods to cope with impact of climate change on biodiversity and ecosystem services and shrinking of biological corridor due to habitat fragmentation were major issues. Besides this, to address these issues, it was also identified from the national consultation workshop of forest officials and experts that most appropriate uniform methods, measures and mechanisms are needed to be developed for the complete assessment, prioritization, analysis and development of action plans to main stream biodiversity conservation and ecosystem services management into operational plan of community forestry.
\end{abstract}

Key words : Biodiversity, community forest, ecosystem services, operational plans

$\mathrm{T}$ The community forestry is the noble innovation of Nepal in the field of participatory forestry and is considered as one of the pioneers of the community based forest management system in the world (Rajpoudel et al., 2014). This programme was evolved in the form of 'Panchayat Forest' and 'Panchayat Protection Forest' in 1978. With the promulgation of the Forest Act, 1993 and Forest Regulations, 1995; the Panchayat and Panchayat Protection Forests were handed over to the forest user groups as 'Community Forest'. In this system, whole or part of the national forests are handed over to local users for the protection, management and utilization of the forest resources, where $100 \%$ of the revenue entirely goes to the community. It was developed to curb the large scale deforestation and degradation rate due to the failure of the government centric forest policy systems in Nepal. Till now, Nepal has handed more than 22 thousand community forests covering more than 2, 237, 670.524 ha to 2, 907, 871 households for protection, management, utilization and benefit sharing of forest resources (DoF, 2018).

1 Bird Conservation Nepal, Email :*parbatkawa123@gmail.com

2 Department of Forests and Soil Conservation 
After initiation of the community forests, degraded forests have been restored into green forests, almost throughout the country owing to significant participation of people in conservation, management and utilization of the forest (Oldekop et al., 2019). Forest Resources of Nepal (19871998) revealed that the deforestation rate was $2.3 \%$ in the hilly areas and $1.3 \%$ in the Terai regions of Nepal, accounting for the average national deforestation rate to be $1.7 \%$ per annum (DFRS, 1999). The most recent forest resource assessment of the Terai and Siwaliks regions of Nepal reported that the deforestation rate has been highly reduced as it was mere $0.44 \%$ (Terai) and $0.18 \%$ per year in Siwalik regions of Nepal (FRA/DFRS, 2014a, 2014b). The existing strict policies applied by the community forest users groups based on Forest Act 2049, like banned to set fires, construction of large buildings, formulation of large pits, hunting or capturing of wild animals, soil erosion encouraging activities, etc. are in favour of the conservation of biological diversity inside the community forests (Padma, 2007, Springate-Baginski et al., 2007). Users' groups are also increasingly adopting different measures for biodiversity conservation in their community forests. The major initiatives carried out from the users' group are : allocation of biodiversity conservation site in their community forest; shifting of tree selection criteria during thinning process from species to tree level characteristics; initiate to maintain all plant species during management interventions on the basis of their condition; conservation of the individual plant species, raise different tree species in nurseries and test their growth rate; removal of thin but pruning of the healthy trees; partially clear areas in densely regenerated sites and regular inventories of tree, their growth cycles and products (Acharya, 2003; Acharya et al., 2007; Padma, 2007; Shrestha et al., 2010). As a result of increased productivity of the forest and restoration of degraded areas, various economic, social, cultural, environmental benefits to the local people such as agricultural productivity (Oli and Manandhar, 2002), food security, human health and nutrition, indigenous knowledge, fuel wood, fiber, wood, fodder, grasses, culture, climate, water resources and aesthetic values (Acharya, 2003; Sharma, 2016) have generated.

In spite of these efforts, the declining rate of many diverse species and scarcity of ecosystem services are still to exist in Nepal. Many species are endangered and many are in the verge of extinction. This indicates that there is still something lacking in the conservation of biodiversity and maintenance of ecosystem services.

Despite of having the important contribution of community forest for biodiversity conservation, the existing legal as well as administrative base (Acharya, 2003) and the management practices in the form of enhancing species diversity and ecosystem functioning is questionable (Shrestha, et al., 2010). The existing forest management approaches in community forestry considered the biodiversity conservation aspect as secondary issues (Acharya, 2003). The Community Forestry $(\mathrm{CF})$ inventory guidelines and practices generally emphasized the timber, fuel wood and fodder production by applying sustainable forest management principle (Pande, 2005; Sharma, 2016). As guided from the CF inventory guidelines, forest conservation approaches of Nepal still focus on timber production (Sharma, 2016). The management intervention prescribed in Operational Plan (OP) based on the existing CF guideline includes the activities like clearing, weeding, thinning and pruning and the perception of Community Forest User Groups (CFUGs) in conserving useful species only rather than lowquality timber trees, shrubs, climbers, grasses and herbs, which could have negative implications for biodiversity (Padma, 2007).

It is always essential to maximize the utilization of forest resources but at the same time we should concerned about conserving the biological diversity and maintaining the ecosystem services in the community forest. Now, it is necessary to scrutinize the operational plans and understand the forest users' perception about biodiversity and ecosystem services related issues. Therefore, this study probes in ground level to understand the status of incorporation of biodiversity conservation and ecosystem services into constitutions and OPs of the CFUGs as well as to assess the gaps and challenges along with appropriate way of improving the status to support policy makers in positioning of the biodiversity and ecosystem services in the future is mandatory.

\section{Materials and methods}

This review was carried out during 2016 and following methods were applied. 


\section{Workshops}

Three regional workshops were conducted taking into consideration the three geographic regions of the country to interact with forest users of different community forests and collect the firsthand information about difficulties on biodiversity conservation and ecosystem management in community forests of Nepal. The participants covering different districts are given in figure 1 .

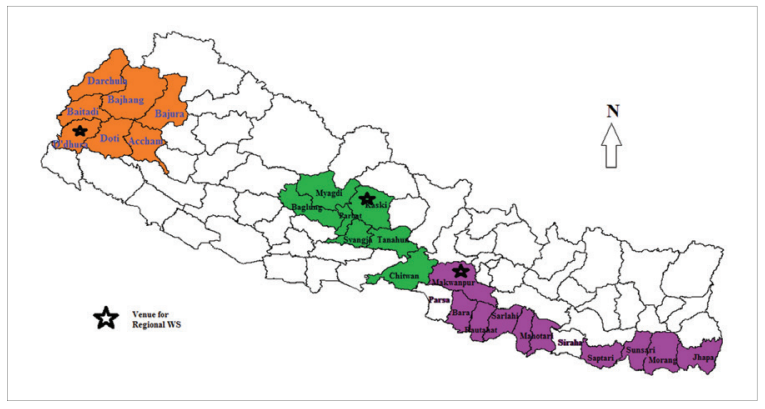

Fig. 1: Districts representing participants and field visits

\section{Review of community forest operational plans}

One hundred operational plans and constitutions from those community forestry user groups who participated in the workshops from the different districts representing different geographic regions were collected and then reviewed. The detail of methodology used for this work is as follows :

\section{Development of indicators}

Indicators for assessing the effective consideration and inclusion of the management of biodiversity (ecosystem, species and genetic levels) and ecosystem services components (provisioning, supporting, regulating and cultural) in CF Operational Plans were developed based on the review of OPs. Further refinement of the developed indicators was done by pretesting with some operational plans of the community forest.

\section{Analysis of confidence index}

To monitor the inclusion of biodiversity and ecosystem services in the community forests, Biodiversity and Ecosystem Services Confidence Index (BESCI) was applied. This index was calculated by converting the qualitative information included in operational plans, by assigning weighted values or scores to each indicator. In each indicator, the highest weighted value 3 was assigned for the more optimistic inclusion (very good, i.e. there has been a comprehensive assessment, prioritization and action plan of biodiversity and ecosystem services - within the parameters of what is required and useful for the purpose of the OP - which are described in detail), 2 weighted value was assigned for optimistic inclusion (good, i.e. a limited number, $>50 \%$ of available Biodiversity (BD) and Ecosystem Services (ES) were described), 1 weighted value was assigned for less optimistic inclusion (mentioned only, i.e. BD and ES are mentioned, but only as a list of resources and services provided by the site, with no description of their use, status, distribution etc.) and 0 weighted value was assigned for no inclusion (i.e. no consideration of $\mathrm{BD}$ and $\mathrm{ES}$ provided by the site apart from the provision of timber and fuel wood). The used indicators to assess values is illustrated in table 1.

Table 1 Used indicators to collect data for the analysis of confidence index

\begin{tabular}{|c|c|c|}
\hline Components & Indicators & Weigh tage value \\
\hline Biodiversity & Tree species & \multirow{14}{*}{$\begin{array}{l}0=\text { No mention } \\
1=\text { Short list as per use } \\
2=\text { Detail list } \\
3=\text { List on the base of Inventory, inclusion of } \\
\text { conservation/protection, management/ development, } \\
\text { use and monitoring }\end{array}$} \\
\hline \multirow[t]{6}{*}{ Flora } & Shrub species & \\
\hline & Herb species & \\
\hline & Bamboo species & \\
\hline & Important species & \\
\hline & Endangered species & \\
\hline & Other (mushroom, lichens etc.) & \\
\hline \multirow[t]{3}{*}{ Fauna } & Mammals & \\
\hline & Reptiles & \\
\hline & Other & \\
\hline \multirow[t]{4}{*}{ Ecosystem services } & Provisioning services & \\
\hline & Regulating services & \\
\hline & Cultural services & \\
\hline & Supporting services & \\
\hline
\end{tabular}


The sum of these assigned weighted values was considered as the diffusion index. The diffusion index was calculated for each indicator (Shamunnay, 2007; FNCCI, 2012).

On the basis of the total score values obtained for the indices, they were classified into three groups for evaluation purpose. These were below average, average and above average. The average value was considered as the benchmark (Shamunnay, 2007; FNCCI, 2012). It thus follows that if :

$\mathrm{BESCI}<$ average, the confidence index was worse,

BESCI $=$ average, the confidence index wasgood, and

BESCI> average, the confidence index was better.

The BESCI of provided operational plans ( $\mathrm{n}$ $=100$ ) was calculated and categorized on the basis of total scores obtained. Then the results regarding the inclusion of biodiversity and ES in community forestry operational plan was analyzed and interpreted.

\section{Consultation workshop}

One national consultation workshop with forest officials was organized to identify the entry point to address the gaps and challenges in mainstreaming biodiversity and ecosystem services into community forest.

\section{Results and discussion}

\section{Results}

\section{Biodiversity and ecosystem services confidence index}

After the analysis of the analyzed data, the inclusion of biodiversity and ecosystem services in the operational plan were found to be below the bench mark (average) table 2. It indicated that the inclusion of ecosystem services and biodiversity in the operational plans of community forests of Nepal are worse.
Table 2: Calculated and benchmark value of BESCI

\begin{tabular}{|c|l|c|c|c|}
\hline SN & Categories & $\begin{array}{c}\text { Calculated } \\
\text { value }\end{array}$ & $\begin{array}{c}\text { Benchmark } \\
\text { value }\end{array}$ & $\begin{array}{c}\text { Confidence } \\
\text { index }\end{array}$ \\
\hline 1. & Biodiversity & 1773.8 & 6552 & Worse \\
\hline 2. & $\begin{array}{l}\text { Ecosystem } \\
\text { services }\end{array}$ & 781.5 & 3150 & Worse \\
\hline
\end{tabular}

\section{Inclusion of biodiversity and ecosystem services in operational plan}

Biodiversity and ecosystem services have been incorporated in the operational plans of the community forest. However, there is still lacking to incorporate many of their components in scientific and systematic way for more fruitful results.

\section{Biodiversity}

Biodiversity conservation term was used in all the operational plans of community forest. Description about availability of diversity in genetic level was absent but out of total species and ecosystem diversity of the community forests, very few species and ecosystem types were mentioned in all community forests' operational plans. Different activities such as conservation, management, utilization, monitoring were concentrated only in limited species despite many opportunities from other species. Comparatively detailed descriptions were recorded from the few operational plans of low land region.

\section{Ecosystem services}

Ecosystem services are the products of biodiversity. Out of total services received by community forest users, detail of two provisioning services, timber and fuelwood, provided by the community forest were described in almost all operation plans. However, broad descriptions regarding the other provisioning services such as food, different raw materials, medicinal and aromatic plants, water etc. along with regulating services, cultural services and supporting services were lacking. The inclusion of the different ecosystem services was found comparatively more in low land and mid-hill regions. 


\section{Biodiversity and ecosystem services management gaps in community forestry}

Biodiversity conservation and ecosystem services have not well been streamlined systematically into the CFs despite its progress in other dimensions due to the lack of methodologies to mainstream biodiversity and ecosystem services into community forest. Some observed lacking in terms of biodiversity and ecosystem services were found as follows :

i. Duplication problem of operational plan: Operational plan should always reflect the real situation and circumstances of concerned community forest. However, many contents of operational plan have suffered from copy and paste problem. Most of the studied operational plan have similar contents of biodiversity and ecosystem services although every community forest is specific in terms of biodiversity and ecosystem services related issues.

ii. Timber oriented operational plan: There are not much strong provisions directly addressing the assessment, conservation and management of available different important biodiversity and ecosystem services in the CF constitutions and operational plans despite many opportunities from them. Rather, it describes about the conservation, management and utilization of some plant resources only which are commercially important from the timber and fuelwood prospective. For this, user groups conduct forest inventory to identify the growing stock and annual allowable cut based on Forest Inventory Guidelines 2057. Community forests are home to many endemic and threatened species and reservoir of ecosystem services but major attention of the CFUGs is on productivity of major forest products rather than addressing wider biodiversity or ecosystem values. Many species that might hold significant importance in future are yet to be identified. Hence, these issues are overlooked in forest management plan and activities like tending operations and other management activities. Even the main document to prepare operational plan "Community Forest Development Programme Guidelines 2071 (third revision)" insists to include biodiversity and ecosystem services related issues into operational plan but, it is silent about methodology to apply those components systematically and scientifically.

iii. Limited provisions about wildlife conservation: Community forests in many cases are confined within the conservation of the floral diversity rather than faunal diversity. While the users are not directly getting benefits from conserving wildlife, they feel less concerned towards wildlife conservation because of the fear of rise in human-wildlife conflict. Human-wildlife conflicts have increased in recent days as the negative outcome of the improved forest status in community forests. The number of various animals have increased such as leopard, porcupine, peacock, wild boar, monkeys, etc. With this increase, the human and livestock injuries and casualties as well as crop depredation and disease transfer have also increased. Most of the operational plans do not prescribe anything about the management and utilization of the wildlife at community forests. However, some good examples of establishment of rescue center and mini zoo by users for the recreational purpose can be seen in very few community forest although their operational plans do not mention anything about it.

iv. Dominant socio-economic factors: Despite the fact that striking balance between socio-economic aspect of the forest users and ecological aspect of the forest is vital for getting direct and indirect benefits at an optimum level, socio-economic factors are more dominant than the ecological and environmental management in community forests. For example, the communities in general do not think about the seed sources, need of including new variety of species etc. and such issues have not been discussed and thoroughly considered during the plantations.

v. Impact of introduced species: The communities have started large scale cultivation of the exotic plants in Terai regions of Nepal for the production of essential oil which increase revenue. The cultivation of Citronella (Cymbopogan witerianus), 
Palmarosa (Cymbopogon martinii), (Cymbopogan citratus), etc. have been extensively planted under the community forests in the region. These species have started covering extensive ground that do not allow the seed dispersal reaching to the ground for germination. Similarly, it is not palatable so not favoured by the wildlife. These kinds of large scale cultivation of exotic species without providing due consideration to the regeneration of the native species may cause negative impacts on the promotion of biodiversity and ecosystem services in community forests. Sometimes, it is very useful to reduce crop depredation by wild animals in the surrounding areas of the protected areas as these are unpalatable to them. Before the cultivation of these species the comprehensive analysis about the regeneration of other species and biodiversity could be done by mentioning into operational plan.

vi. Impact of invasive and alien species: Community forests have been largely infested by Invasive and Alien Species (IAS). Those forests which are near to disturbances such as road, settlement, landslide and barren areas have been heavily infested by large number of IAS. The most chronic are Eupatorium species, Lantana camara, Mikania micrantha, Ageratina adenophora and $A$. odorata. These heavy invasions of the alien species have negatively impacted in the natural regeneration of the desired species. It has further increased the risk of forest fire and forest degradation in community forests of Nepal. The community forests of the eastern Nepal have recorded more invasions compared to the western regions of Nepal. Most of the operational plans are not aware appropriately about eradicating this evil.

vii. Impact of climate change: The impact of climate change on biodiversity and ecosystem services are also visible such as change in phenological characters, reduction of water resources, stream drought, forest fire, etc. are some examples. Most of Climate Change Adaptation Plan of OPs are focused on community level Adaptation Plan. In fact, operational plans are less attensive in the positive and negative impact over forest products (biodiversity and ecosystem services). It will better to prepare action plan under OP with the view of addressing Climate Change (CC) impact over biodiversity and ecosystem services.

viii. Shrinkage of biological corridor: Habitat fragmentation is increasing every year due to population growth, deforestation, encroachment, land use land cover change, both illegal and legal settlements, different infrastructure development activities such as road construction, electric transmission line expansion etc. However, some community forest user groups have been trying to maintain harmony among conservation, management and sustainable development through preparation and strong implementation of appropriate operational plan but there is huge lack of coordination and collaboration among community forest user groups and relevant stakeholders in terms of exchanging their good experiences and practices in conservation and management of biodiversity and ecosystem services.

\section{Entry point to address the gaps and challenges}

Community forest consists of remarkable number of important biodiversity (flora and fauna) and provide different ecosystem services to user groups from there. However, operational plan does not have facts about exact biodiversity and ecosystem services that are available inside the community forest. It only explains the name of very few wild flora and fauna and ecosystem services instead of their complete assessment. There is neither any prioritization of biodiversity and ecosystem services in terms of necessity, utility and threatened status nor analysis and appropriate management or action plan to cope with the challenges and issues of those prioritized biodiversity and ecosystem for their conservation and sustainable usage. Therefore, it was concluded that methodology for the complete assessment, prioritization, analysis and development of action plan is needed to apply for the incorporation of biodiversity and ecosystem services related issues into operational plan. The strict implementation of this action plan is believed to address the above mentioned issues and support in biodiversity conservation and maintenance of ecosystem services and ultimately, to ensure livelihood improvement as well. 


\section{Discussion}

The success of community forestry can be exemplified in terms of ecological and socioeconomical perspectives (Shrestha et al., 2010). These successes can be signified from the different attributes like restoring degraded land and habitats, conserving biodiversity, increasing supply of forest products, empowering women and disadvantaged groups, generating rural incomes and developing human resources (Shrestha et al., 2010; Sharma, 2013). Therefore, the conservation and improvement of biodiversity and ecosystem services is directly linked with the success of community forest. However, the above findings point to the worse incorporation of biodiversity conservation and ecosystem services related issues into the operational plan as operational plan is the main component to lead the destination of community forest. The findings showed that there are some gaps in community forestry operational plan which have not favoured biodiversity conservation and ecosystem services management systematically in optimum level which consists of duplicate problem of biodiversity and ecosystem services related issues in operational plans, timber oriented operational plan; limited provision about wildlife conservation and negative perception of people on wildlife conservation owing to human wild life conflict; dominant socio-economic factors; impact of introduced species, invasive and alien species; lacking in provision of adaptation and mitigation methods to cope with impact of climate change on biodiversity and ecosystem services and shrinking of biological corridor due to habitat fragmentation. Many authors (Pande, 2005; Pandit and Bevilacqua, 2011; Charmakar, et al., 2016; Padma, 2007; Sharma, 2016) had made similar perspectives and agreed that there is still something lacking in systematic conservation of biodiversity and ecosystem services. (Acharya, 2003; Shrestha et al., 2010) also clarify that inconsistent understandings about biodiversity, its components, types, importance and subsistence need priority over conservation are the major constraints for biodiversity conservation in community forest. Similarly, (Chowdhary and $\mathrm{KC}$, 2016) elucidate that despite numerous tangible benefits from community forests and its record maintenance; its ecological values and importance such as carbon sequestration, hydrological services, aesthetic and spiritual parts are partly missing and largely forgotten from the prevalent community forestry programme. These points indicate that biodiversity and ecosystem services have been altered or not main streamed community forest system due to the current management interventions inside community forest.

More recently, the issues of biodiversity conservation and ecosystem services have been incorporated in Community Forestry Guidelines (2009). It is yet not free from the traditional utilitarian concept; under the guide-lines, CFUGs have to make inventory of only useful plants, not all the species reside in the forests. The usefulness again is based on the personal judgment and state of knowledge. Thus, it would not make a significant change on current management practices, practices which have been turning diverse forest into monoculture.

Therefore, the finding concluded that the methodology for the complete assessment, prioritization, analysis and development of action plan is needed to incorporate the biodiversity and ecosystem services related issues into operational plan. And, to maintain uniformity in incorporation of $\mathrm{BD}$ and $\mathrm{ES}$ issues in all community forests over the nation, Community Forest Development Programme Guidelines should make necessary to follow it for the better conservation and management of biodiversity and ecosystem services.

\section{Conclusion}

In this paper, we identified that biodiversity conservation and ecosystem services have not been streamlined systematically into the community forests. The study showed that the incorporation status of biodiversity and ecosystem services into operational plan is worse as this plan is the main component to lead the destination of any community forest and the study also found some gaps and challenges in community forestry which have not favoured to biodiversity conservation and ecosystem services management systematically in optimum level yet. Among them, duplication of the problem of biodiversity and ecosystem services related issues in operational plan; timber oriented operational plan; limited provision about wildlife conservation and negative perception of people 
on wildlife conservation owing to human wild life conflict; dominant socio-economic factors; impact of introduced species, invasive and alien species; lacking in provision of adaptation and mitigation methods to cope with impact of climate change on biodiversity and ecosystem services and shrinking of biological corridor due to habitat fragmentation were observed major issues.

Considering the crucial role of biodiversity and ecosystem services for the prosperity of local people, most appropriate uniform methods, measures and mechanisms are needed to be developed for the complete assessment, prioritization, analysis and the development of action plan is needed to mainstream biodiversity conservation and ecosystem services management into operational plan of community forestry.

\section{References}

Acharya, K. P. 2003. "Conserving biodiversity and improving livelihoods : The case of community forestry in Nepal" paper presented at the International Conference on Rural Livelihoods, Forests and Biodiversity, Bonn, Germany.

Acharya, K. P., Goutam, K. R., Acharya, B. K. and Gautam G. 2007. Participatory assessment of biodiversity conservation in community forestry in Nepal. Banko Jankari 16 (1) : 46-56.

Charmakar, S., Pandey, A., Joshi, N. and Khanal, S. C. 2016. Participatory Biodiversity Monitoring in Community Forests : A Methodological Discussion Based on Experience of Nepal. In Mainstreaming Biodiversity and Ecosystem Services in Nepal. Bird Conservation Nepal, Kathmandu, 117-127.

Chowdhary, C. and KC, Rajendra. 2016. Biodiversity and ecosystem services : Neglected aspects of the community forestry systems in Nepal. In Mainstreaming Biodiversity and Ecosystem Services in Nepal, Bird Conservation Nepal, Kathmandu, 41-50.

DFRS. 1999. Forest Resources of Nepal. Department of Forest Research and Survey,
Babarmahal, Kathmandu, Nepal.

FRA/DFRS. 2014 a. Churia Forests of Nepal. In Forest Resource Assessment (FRA), Department of Forest Research and Survey (DFRS), Ministry of Forest and Soil Conservation (MoFSC), Government of Nepal, Kathmandu.

FRA/DFRS. 2014 b. Terai forests of Nepal. In Forest resource assessment (FRA), Department of Forest Research and Survey (DFRS), MoFSC, Government of Nepal, Kathmandu.

DoF. 2018. Community Forestry Bulletin. Department of Forests, Babarmahal, Kathmandu, Nepal.

Oldekop, J. A., Sims, K. R. E., Karna, B. K., Whittingham, M. J., and Agrawal, A. 2019. Reductions in deforestation and poverty from decentralized forest management in Nepal. Nature Sustainability. 10. 1038/ s41893-019-0277-3.

Oli, K. P. and Manandhar, M. S. 2002. The role of forest in supplying soil nutrients in agricultural production system in the mid hills of Nepal. BankoJankari 12 (1) : $27-$ 34.

Padma, T. V. 2007. Community forestry : the regreening of the Himalayas : Leafy forests replanted by communities in Nepal are flying in the face of accepted conservation practice, reports. Spotlight, http :// www. scidev. net/global/policy/feature/ community-forestry-the-regreening-ofthe-himalaya. html\#

Pande, R. S. 2005. Pro-poor Community Forage Production Programme in the Nepal Australia Community Resource Management and Livelihoods Project, Nepal. Proceedings of the Workshop on Fodder Oats, Fodder Technology Packages and Small Farm Income Generation. FAO 8-11 March 2005.

Pandit, R. and Bevilacqua, E. 2011. Forest users and environmental impacts of community forestry in the hills of Nepal. Forest Policy 
and Economics $13: 345-352$.

Rajpoudel, N., Fuwa, N. and Otsuka, K. 2014. The impacts of a community forestry program on forest conditions, management intensity and revenue generation in the Dang district of Nepal. GRIPS Discussion Paper 13-24.

Sharma, B. K. 2013. Wildlife and their habitat in lowland areas of Chitwan National Park's Buffer Zone in Nepal : two decades of community conservation approach. $\mathrm{Ph} \mathrm{D}$ thesis, Mizoram University, India.

Sharma, S. P. 2016. Overview of Community Forestry Inventory Policy and Plant Biodiversity Management and its Implications. In Mainstreaming Biodiversity and Ecosystem Services in Nepal. Bird Conservation Nepal, Kathmandu, 57-64.
Shrestha, U. B., Shrestha, B. B. and Shrestha, S. 2010. Biodiversity conservation in community forests of Nepal : Rhetoric and reality. International Journal of Biodiversity and Conservation 2 (5) : 98104.

Springate-Baginski O., Dev O. P., Dhungana H., Dahal S. and Dutta I. C. 2007. CommunityBased Forest Biodiversity Management - Concepts and Tools : help people to reconcile forest biodiversity management with their livelihood development. Hillside Press. 200 P. 